\title{
PEMBIBITAN TANAMAN HIAS UNTUK PENINGKATAN LIFE SKILL ANAK-ANAK PANTI ASUHAN SOS DESA TARUNA TABANAN BALI
}

\author{
M. Pharmawati ${ }^{1}$, A.A. Sukmaningsih ${ }^{2}$, I.W. Arnata ${ }^{3}$, I. Setyawati ${ }^{4}$
}

\begin{abstract}
ABSTRAK
Tanaman hias merupakan semua jenis tanaman yang bermanfaat untuk menambah keindahan baik di dalam maupun di luar ruangan. Minat masyarakat terhadap tanaman hias semakin meningkat, sehingga usaha tanaman hias merupakan usaha yang dapat meningkatkan penghasilan. Desa Taruna SOS adalah nama panti asuhan di Banjar Bunur Puhun, Desa Bantas, Kecamatan Selemadeg Timur, Tabanan, Bali. Panti asuhan ini terdiri dari 12 rumah yang mengasuh anak-anak yang kehilangan pengasuhan orang tua dan anak-anak yang miskin. Untuk meningkatkan skill anak-anak panti asuhan sehingga dapat membuka bisnis, maka dilakukan pelatihan pembibitan tanaman hias. Metode yang digunakan terdiri dari metode ceramah, praktek dan diskusi yang meliputi pengenalan jenis-jenis tanaman hias, pengenalan berbagai media tanam dan pemeliharaan. Kegiatan diikuti oleh pembina panti asuhan, tenaga sukarelawan di SOS dan anak-anak SOS Desa Taruna. Tanaman yang ditanam adalah tanaman hias daun Tradescantia sp, Calathea sp, Sansevieria sp., sirih gading belanda, serta tanaman bunga pukul sembilan (Portulaca sp) dan bunga ruwelia (Ruellia malacorperma).
\end{abstract}

Kata Kunci : pembibitan, SOS Desa Taruna, tanaman hias

\begin{abstract}
Ornamental plants are all plants used for decorative purposes to add an aesthetic value of certain places both outdoor and indoor. There is an increasing public interest to grow ornamental plants. Ornamental plant business is promising business to create income. Desa Taruna SOS is an orphanage located at Banjar Bunur Puhun, Desa Bantas, Kecamatan Selemadeg Timur, Tabanan, Bali. The orphanage consists of 12 houses that take care of children who have lost parental care and children from poor families. To improve skills of orphanage children, training on ornamental plant cultivation and nursery was done. The method used consists of lecture, practical activities and discussion including introduction of ornamental plant types, introduction of various planting media and maintenance. The activity was attended by the orphanage manager, volunteers at SOS and children of SOS Desa Taruna. Ornamental plants planted were ornamental foliage plants such as Tradescantia sp, Calathea sp, Sansevieria sp., sirih gading belanda/srigading, and ornamental flower plants such as bunga pukul sembilan (Portulaca sp) and bunga ruwelia (Ruellia malacorperma).
\end{abstract}

Keywords : plant nursery, SOS Desa Taruna, ornamental plants

\footnotetext{
${ }^{1}$ Staf Pengajar Program Studi Biologi, Fakultas MIPA, Universitas Udayana, made_pharmawati@unud.ac.id.

${ }^{2}$ Staf pengajar Program Studi Biologi, Fakultas MIPA, Universitas Udayana, asukmaningsih@yahoo.com

${ }^{3}$ Staf pengajar Fakultas Teknologi Pertanian, Universitas Udayana,

${ }^{4}$ Staf Pengajar Program Studi Biologi Fakultas MIPA, Universitas Udayana, iriani_setyawati@unud.ac.id
} 


\section{PENDAHULUAN}

Tanaman hias tidak hanya berfungsi sebagai hiasan tetapi juga dapat menyerap polutan, sehingga tanaman hias merupakan komponen penting baik di dalam maupun di luar ruangan. Umumnya jenis tanaman hias yang populer di masyarakat antara lain tanaman jenis anggrek dan bungabungaan lainnya seperti Begonia, Euphorbia. Di samping itu tanaman hias daun seperti Sansiviera, puring juga banyak ditanam misalnya di perkantoran maupun sekolah-sekolah. Budidaya dan pemeliharaan tanaman hias seperti disebutkan di atas relatif mudah dilakukan. Menurut Febriarta et al (2012), tanaman hias memiliki fungsi utama sebagai visual control, physical barriers, climate control, erosion control, wildlife habitat dan aesthetic values.

Perbanyakan dapat dilakukan melalui biji, stek atau tunas. Jika pembibitan tanaman hias benarbenar serius dikerjakan, tanaman hias ini dapat dapat menjadi hobi yang menghasilkan uang melalui penjualan bibit dan penyewaan tanaman hias, maupun penjualan bunga potong. Di samping itu, kegiatan pembibitan ini dapat dijadikan satu cara untuk melindungi flora asli Indonesia dan konservasi lingkungan secara berkelanjutan di masa mendatang.

Tanaman hias daun yang populer diantaranya jenis tanaman hias daun seperti gelombang cinta, Dieffenbachia, Aglaonema maupun keladi-keladian (Terra, 2009). Tanaman Sansiviera atau dikenal dengan nama lokal lidah mertua juga banyak menarik perhatian. Tanaman ini merupakan tanaman hias daun yang dapat berfungsi sebagai agen yang menyerap polutan. Tanaman ini dapat diperbanyak dengan anakan atau dengan stek daun.

Tanaman hias bunga yang dapat diperbanyak dengan stek daun adalah Begonia. Dari banyak jenis Begonia yang telah dikoleksi, terdapat jenis menarik misalnya Begonia acetosa yang mempunyai daun indah berwarna hijau dan permukaan bawah berwarna merah menyala dengan tekstur lembut seperti beludru. Jenis-jenis Begonia rex sebagai jenis andalan mempunyai tampilan daun yang beraneka warna dan sangat menarik seperti hijau muda, hijau tua, hijau menyala, merah, lembayung, keperakan atau kombinasi warna-warna yang indah. Tekstur daunnya juga menampilkan bentuk yang unik misalnya lembut seperti beludru, kasar, berbingkul, mengkerut dan keriting (Siregar et al., 2007). Anggrek adalah tanaman hias bunga yang sangat populer. Bibit anggrek dalam botol banyak tersedia di toko tanaman hias. Pemindahan bibit anggrek dari dalam botol ke media luar memerlukan tahapan aklimatisasi yang memerlukan media tumbuh yang tepat (Astutik, 2006). Teknik ini harus dikuasai jika melakukan membudidayakan tanaman anggrek.

Ketrampilan perbanyakan tanaman hias sangat bermanfaat bagi para pemuda. Dengan memiliki teknik perbanyakan tanaman hias yang baik, maka terbuka peluang usaha pembibitan tanaman hias (Rahayu, 2006). Permintaan tanaman hias semakin meningkat karena sekarang ini fungsi tanaman hias bukan hanya berfugsi estetis saja, tetapi juga menjadi media komunikasi (ucapan selamat melalui bunga) maupun fungsi terapi. Sehingga diperlukan pengetahuan mengenai perkembangbiakan yang cepat dan tepat.

Di Kota Denpasar dan Kabupaten Badung, bisnis tanaman hias sangat menjanjikan. Banyaknya hotel, perkantoran, an perumahan yang dibangun serta perkembangan pariwisata, memerlukan banyak jenis tanaman hias. Seminar-seminar maupun conference yang banyak diadakan di bali, memerlukan pula tanaman hias sebagai dekorasi ruangan, sehingga bisnis tanaman hias dapat melebar kepada penyewaan tanaman untuk kepentingan tersebut.

Desa taruna SOS adalah nama panti asuhan yang berlokasi di Banjar Bunur Puhun, Desa Bantas, Kecamatan Selemadeg Timur, Tabanan, Bali. Anak-anak dalam panti asuhan ini dididik berbasis keluarga. Sesuai namanya, panti asuhan ini terdiri dari banyak rumah atau KK selayaknya sebuah

\section{1 | BULETIN UDAYANA MENGABDI}


desa. Keluarga-keluarga tersebut mengasuh anak-anak yang kehilangan pengasuhan orang tua dan anak-anak yang memiliki orang tua yang miskin. Tujuan kegiatan ini adalah memberikan pelatihan pembibitan tanaman hias kepada anak-anak Panti Asuhan SOS. Diharapkan melalui kegiatan ii, tanaman hias yang dikembangkan dapat dijual atau disewakan sehingga dapat menjadi sumber penghasilan. Hal ini akan dapat membantu mereka untuk bisa mandiri ataupun mengembangkan bisnis di kemudian hari.

Pengenalan ketrampilan perbanyakan tanaman hias juga dapat sebagai sarana untuk meningkatkan kecintaan para pemuda terhadap lingkungan. Melalui ketrampilan perbanyakan dan budidaya tanaman hias baik manfaat komersial, estetika dan pelestarian lingkungan dapat diperoleh terutama bagi anak-anak panti asuhan, sehingga dapat dimanfaatkan untuk usaha pembibitan tanaman hias.

Sasaran strategis pada kegiatan ini adalah anak-anak di SOS Desa Taruna, Tabanan, Bali. Desa Taruna SOS adalah nama panti asuhan di Banjar Bunur Puhun, Desa Bantas, Kecamatan Selemadeg Timur, Tabanan, Bali. Panti asuhan ini terdiri dari banyak KK yang mengasuh anakanak yang kehilangan pengasuhan orang tua dan anak-anak yang miskin. Panti asuhan ini merupakan panti asuhan berbasis keluarga. Anak-anak tersebut memerlukan program pemberdayaan keluarga sehingga dapat membantu keluarga asuh dan memiliki peluang mendapat penghasilan.

\section{METODE PELAKSANAAN}

Pada kegiatan pembibitan tanaman hias ini, metode yang dignakan adalah (1) Identifikasi masalah dengan kunjungan ke SOS Desa Taruna, Banjar Bunur Puhun, Desa Bantas, Kecamatan Selemadeg Timur, Tabanan, Bali; (2) Pengumpulan bahan pelatihan pembibitan tanaman berupa bbit tanaman hias dan stek tanaman hias, medium tanah, pot, pembeliat alat-alat berkebun dan pupuk. Media yang digunakan untuk tanaman hias daun adalah pasir: tanah: kompos $(1 ; 1 ; 1)$ (Andiani, 2012); (3) Ceramah yang merupakan teori perbanykan tanaman, (4) Praktek pembibitan tanaman hias, (5) Diskusi dan (6) Evaluasi.

Ceramah yang dilakukan merupakan transfer ilmu mengenai macam-macam tanaman hias, yaitu yaitu tanaman hias bunga, tanaman hias daun, tanaman hias buah, tanaman hias akar, dan tanaman hias batang beserta contoh masing-masing (Andrianto dan Novo, 2004). Ceramah juga meliputi cara perbanyakannya serta pemeliharaan yang diperlukan. Tanaman hias yang digunakan merupakan tnaman hias daun dan bunga dengan perbanyakan melalui stek pucuk atau batang dan dengan tunas. Kegiatan praktek penanaman mencakup persiapan media tanam, persiapan stek tanaman dan penanaman. Tanaman Tradescantia, bunga ruwelia (Ruellia malacorperma) dan bunga pukul sembilan diperbanyak dengan stek pucuk. Sansevieria diperbanyak dengan tunas dan stek daun (Sulistiana, 2013). Pembibitan tanaman hias daun Calathea sp menggunakan rimpang/anakan (Ratnasari, 2008). Diskusi dilakukan pada saat praktek penanaman agar anakanak dapat melakukan cara pembibitan dengan baik. Evaluasi pelaksanaan kegiatan dilakukan dua kali berupa pengamatan terhadap pertumbuhan tanaman hias yang ditanam.

\section{HASIL DAN PEMBAHASAN}

Kegiatan dilakukan mulai tanggal 30 Juli 2017 dengan melakukan kunjungan ke Panti Asuhan SOS Desa Taruna, Banjar Bunur Puhun, Desa Bantas, Kecamatan Selemadeg Timur, Tabanan, Bali. Kegiatan pembibitan tahap pertama dilakukan tanggal 13 Agustus 2017, evaluasi dilakukan tanggal 18 September 2017, dan kegiatan pembibitan tahap kedua dilakukan tanggal 22 Oktober 2017.

VOLUME 17 NOMOR 2, APRIL 2018 | 92 
Kegiatan tanggal 13 Agustus diikuti oleh 54 anak Panti Asuhan SOS Desa Taruna, 1 pengurus panti asuhan dan 2 tenaga sukarelawan di panti asuhan tersebut. Kegiatan evaluasi tada tanggal 18 september dilakukan bersama-sama dengan pengurus panti asuhan. Kegiatan tahap kedua pada tanggal 22 Oktober 2017 diikuti oleh 10 anak panti asuhan. Tanaman hias yang digunakan pada praktek pembibitan adalah tanaman hias daun Tradescantia sp, Calathea sp, Sansevieria sp., sirih gading belanda/srigading, puring, serta tanaman bunga pukul sembilan (Portulaca sp) dan bunga ruwelia (Ruellia malacorperma). Gambar 3.1 merupakan cara pembibitan tanaman ruwelia (Ruellia malacorperma) yang diberikan kepada anak-anak Panti Asuhan SOS. Batang tanaman ruwelia bagian atas dipotong dan direndam dalam air. Setelah lima hari, akar mulai muncul dan siap ditanam di tanah. Potongan batang tanaman ruwelia dapat langsung ditanam di tanah. Gambar 3.2 merupakan kegiatan persiapan media tanam dan pnanaman bibit tanaman hias.

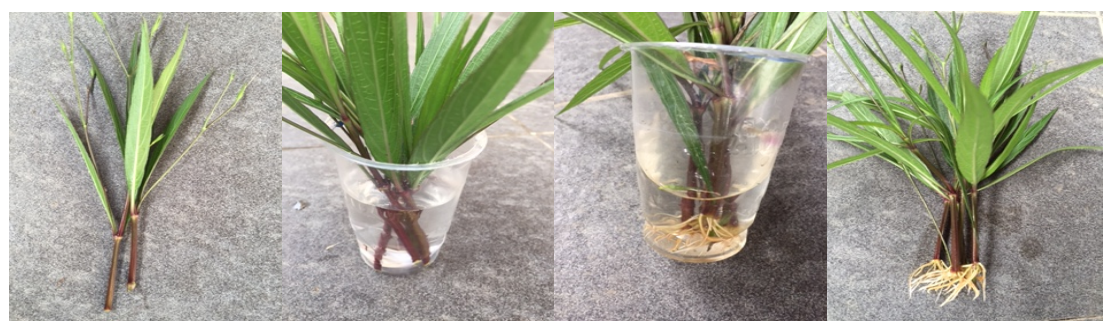

Gambar 3.1. Perbanyakan Tanaman Bunga Ruwelia (Ruellia malacorperma).

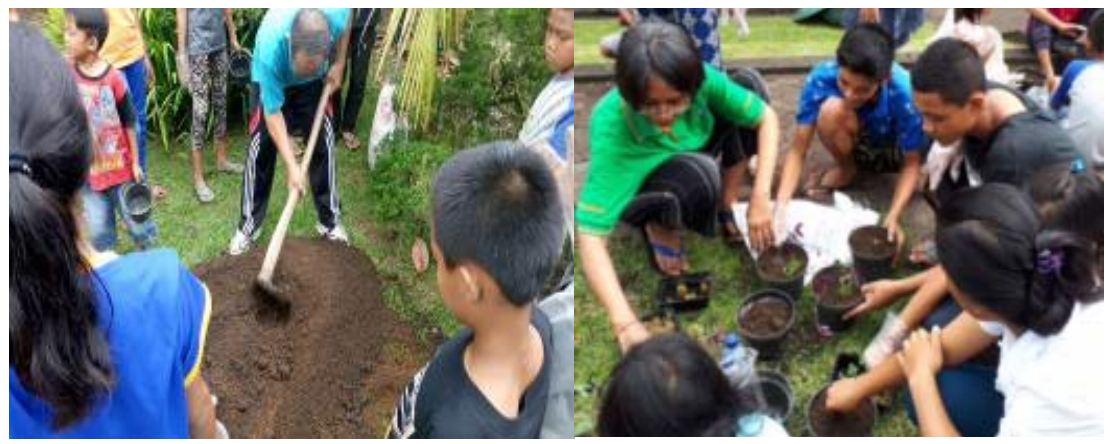

Gambar 3.2. Kegiatan Penyiapan Media Tanam dan Pembibitan Tanaman Hias

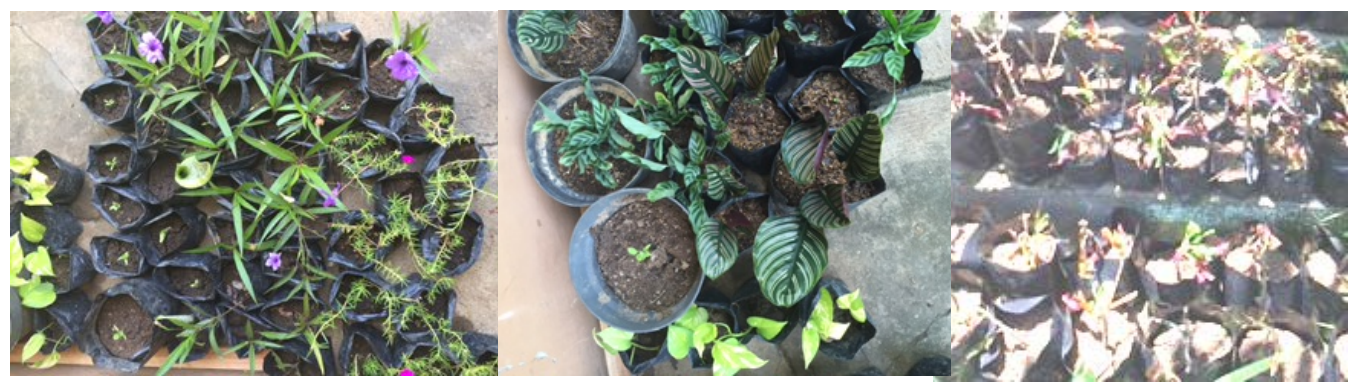

Gambar 3.3. Hasil Perbanyakan tanaman Hias

Tanaman hias yang sudah mulai tinggi dapat dipotong dan ditanam kembali agar jumlah tanaman menjadi semakin banyak. Perbanyakan tanaman dengan cara stek.merupakan cara yang paling 
mudah dan cepat dilakukan untuk mendapatkan tanaman dalam jumlah banyak untuk memenuhi kebutuhan bibit tanaman dalam skala besar (Nurlaeni dan Surya, 2015).

\section{KESIMPULAN}

Kegiatan pembibitan tanaman hias di panti Asuhan SOS Desa dapat menyediakan bibit tanaman hias yang dapat dijual untuk menambah penghasilan. Cara perbanyakan yang sederhana yaitu stek dapat menghasilkan tanaman dalam jumlah banyak yang siap dijual.

\section{UCAPAN TERIMAKASIH}

Kegiatan ini didanai oleh Universitas Udayana melalui Hibah Udayana Mengabdi DIPA PNBP Universitas Udayana Sesuai Surat Perjanjian Penugasan Pelaksanaan Pengabdian kepada Masyarakat Nomor: 67466/UN14.4.A/PM/2017

\section{DAFTAR PUSTAKA}

Andrianto, T.T. dan Novo (2004) Budidaya Taaman Hias Berdaun Indah. Penerbit Absolut, Jogiakarta Astutik (2006). Uji Berbagai Media Pada Aklimatisasi Hibrida Dendrobium. Buana Sains 6(1): 89-92

Febriarta, H.A., E. Sulistyaningsih., S.N.R. Irwan (2012). Identifikasi Karakteristik dan Fungsi Tanaman Hias untuk Taman Rumah di Dataran Medium dan Dataran Rendah. Vegetalika 1 (1): 11-22

Nurlaeni, Y., M.I. Surya (2015) Respon Stek Pucuk Camelia japonica terhadap Pemberian Zat Pengatur Tumbuh Organik. Prosiding Seminar Nasional Mayarakat Biodiversitas Indonesia 1(5): 1211-1215

Rahayu, M. (2006) Peluang bisnis anggrek. Departemen Pertanian

Ratnasari, J. (2008) Galeri Tanaman Hias Daun. Penebar Swadaya, Bogor.

Siregar, H., I.M. Ardaka, M. Siregar. (2007) Masa Berbunga 22 Jenis Begonia Alam di Kebun Raya "Eka Karya" Bali. Biodiversitas 8 (3): 192-196

Sulistiana, S. (2013) Respon Pertumbuhan Stek Daun Lidah Mertua (Sansevieria parva) Pada Pemberian Zat Pengatur Tumbuh Sintetik (ROOTONE-F) Dan Asal Bahan Stek. Jurnal Matematika, Sains, dan Teknologi, 14 (2) 107-118

Terra, A.H. 2009. 600 jenis Tanaman Hias Daun. Penerbit Gramedia, Jakarta. 